\title{
Using behaviour change and implementation science to address low referral rates in oncology
}

Janet C. Long ${ }^{1 *}$ D , Deborah Debono ${ }^{1,2}$, Rachel Williams ${ }^{3,4}$, Elizabeth Salisbury ${ }^{5}$, Sharron O'Neill ${ }^{6}$, Elizabeth Eykman', Jordan Butler ${ }^{5}$, Robert Rawson ${ }^{8}$, Kim-Chi Phan-Thien', Stephen R. Thompson ${ }^{3,4}$, Jeffrey Braithwaite', Melvin Chin $^{3}$ and Natalie Taylor ${ }^{1,10}$

\begin{abstract}
Background: Patients undergoing surgery for bowel cancer now have a routine screening test to assess their genetic predisposition to this and other cancers (Lynch syndrome). A result indicating a high risk should trigger referral to a genetic clinic for diagnostic testing, information, and management. Appropriate management of Lynch syndrome lowers morbidity and mortality from cancer for patients and their family, but referral rates are low. The aim of this project was to increase referral rates for patients at high risk of Lynch syndrome at two Australian hospitals, using the Theoretical Domains Framework (TDF) Implementation approach.
\end{abstract}

Methods: Multidisciplinary teams at each hospital mapped the referral process and discussed barriers to referral. A 12-month retrospective audit measured baseline referral rates. The validated Influences on Patient Safety Behaviours Questionnaire was administered to evaluate barriers using the TDF. Results were discussed in focus groups and interviews, and interventions co-designed, guided by theory. Continuous monitoring audits assessed change in referral rates.

Results: Teams $(n=8,11)$ at each hospital mapped referral processes. Baseline referral rates were $80 \%(4 / 5)$ from 71 screened patients and 8\% (1/14) from 113 patients respectively. The questionnaire response rate was 51\% (36/71). Most significant barrier domains were: 'environmental context;' 'memory and decision making;' 'skills;' and 'beliefs about capabilities.' Focus groups and interviews with 19 healthcare professionals confirmed these domains as significant. Fifteen interventions were proposed considering both emerging and theory-based results. Interventions included: clarification of pathology reports, education, introduction of e-referrals, and inclusion of genetic status in documentation.

Audits continued to December 2016 showing a change in pathology processes which increased the accuracy of screening. The referral rate remained low: $46 \%$ at Hospital A and 9\% Hospital B. Results suggest patients who have their referral deferred for some reason are not referred later.

Conclusion: Lynch syndrome is typical of low incidence problems likely to overwhelm the system as genomic testing becomes mainstream. It is crucial for health researchers to test methods and define generalizable solutions to address this problem. Whilst our approach did not improve referrals, we have deepened our understanding of barriers to referral and approaches to low frequency conditions.

Keywords: Implementation, Theoretical domains framework, Behaviour change, Hereditary cancer, Pathology, Referral, Systems change

\footnotetext{
* Correspondence: janet.long@mq.edu.au

${ }^{1}$ Centre for Healthcare Resilience and Implementation Science, Australian Institute of Health Innovation, Faculty of Medicine and Health, Macquarie University, Sydney, NSW, Australia

Full list of author information is available at the end of the article
}

(c) The Author(s). 2018 Open Access This article is distributed under the terms of the Creative Commons Attribution 4.0 International License (http://creativecommons.org/licenses/by/4.0/), which permits unrestricted use, distribution, and reproduction in any medium, provided you give appropriate credit to the original author(s) and the source, provide a link to the Creative Commons license, and indicate if changes were made. The Creative Commons Public Domain Dedication waiver (http://creativecommons.org/publicdomain/zero/1.0/) applies to the data made available in this article, unless otherwise stated. 


\section{Background}

A key challenge to the delivery of safe, high quality health services is healthcare professionals' ability to remain abreast of new research and to translate these new understandings into feasible and appropriate clinical practice [1]. One field in particular that is rapidly generating new clinically relevant research and guidelines which require an active implementation effort is cancer genomics. Whilst there is incredible potential for these scientific discoveries to improve diagnosis and treatment of patients, the translation of each new piece of genetic evidence into clinical practice is complex, challenging, and slow [2].

One such example is Lynch Syndrome (LS). LS is a hereditary condition associated with a high incidence of colorectal, endometrial and a range of other cancers $[3,4]$. Screening tests that identify people with a high risk of LS have been shown to reduce morbidity and mortality and to be cost effective $[5,6]$. Screening consists of consideration of the patient's clinical presentation, family history and pathology testing of a tumour sample. Universal screening is not yet fully implemented in Australian hospitals with individual pathology and oncology departments applying an ad hoc screening practice. Currently, all patients undergoing surgery for $\mathrm{CRC}$ have routine immunohistochemistry (IHC) for four mismatch repair genes performed on their tumour to determine risk of LS. A secondary screening test (IHC for BRAF V600E) for a subset of patients may now also be performed to distinguish tumours likely to be due to a faulty gene from those that are not. At the commencement of the study, this secondary screening test was not in place at either pathology department. However, one of the pathology laboratories commenced this more than half way through the study. Patients with CRC who present with additional clinical factors such as a young age or a strong family history of bowel cancer may be flagged as having a high risk of LS before surgery, but the IHC is still performed to help identify which of the four Mismatch Repair genes are involved. High risk results are ideally acted on by referring the patient to a Familial Cancer Clinic (FCC), which provides counselling, assesses the risk further and arranges diagnostic genetic testing if appropriate [7]. Once diagnosed, risk can be managed by appropriate surveillance, and consideration of prophylactic surgery. Family members can also be informed and tested, as appropriate. As an autosomal dominant condition, family members have a $50 \%$ chance of inheriting the faulty gene. Lynch Syndrome Australia, an advocacy group for people living with LS, stresses the importance of access to high quality information and counselling from a genetic service, ideally an FCC as part of the testing process [8]. Australian [6, 9, 10] and international [11-13] evidence however, indicates that LS is underdiagnosed, one cause of which is low referral to genetic services of at risk patients identified by screening tests. This paper presents the case of LS, where local concerns of genetic specialists, and (unpublished) audits of screening tests being incorporated into practice over the last five years in Australian hospitals, have not yet succeeded in raising the low rate of diagnosis of this hereditary cancer syndrome.

Implementation science recognises that practice change is often not achieved simply by disseminating the findings of the latest clinical trial or systematic review [14]. An understanding of context, current work flows, and barriers to change are essential to tailor new interventions to be an acceptable fit with existing practices. At the same time, there is a need for effective, generalizable, and replicable interventions suitable for similar healthcare contexts to avoid unnecessary replication and effort [15]. An understanding of the theoretical underpinnings of both the problem (barriers) and the use of evidence based and pragmatic solutions (interventions) can greatly assist this. Here we demonstrate how we used the validated, six step Theoretical Domains Framework Implementation (TDFI) approach - which combines behaviour change theory with implementation science, to translate LS evidence into practice [16-18].

The aim of our project was to increase recognition of high risk patients and subsequent referrals to the FCC. We used the TDFI approach to structure activities to address the problem [17], using audits of IHC results and referrals to assess change.

\section{Methods \\ Overview}

The study was conducted in two large Australian hospitals with no clearly documented screening protocol but wide circulation of Evi-Q guidelines [7] (evidence-based guidelines used in Australia to guide cancer treatment and management). There was evidence clinicians' familiarity with clinical presentations and family history that suggested a high risk of LS. Hospital A performed surgery on around 75 patients with CRC per year, while Hospital B performed surgery on around 120 patients with CRC per year. Investigators were drawn from health services research, clinical practice (genetics, surgery, medical and radiation oncology and pathology) and two experienced consumer partners, one living with LS. The six step TDFI process was as follows. Step 1: multidisciplinary implementation teams were formed at each hospital to process map LS referrals and discuss barriers. Step 2: a baseline audit of CRC surgery patients and LS genetic testing referrals were completed at each hospital to populate the process maps with objective data and determine the extent of the problem. Step 3: health professionals involved with CRC patients were invited to complete the validated Influences on Patient Safety 
Behaviours Questionnaire (IPSBQ) [19] to identify barriers to referrals, which was followed up by TDFguided focus groups to verify the referral barriers. Step 4: interventions were co-designed with health professionals using evidence-based behaviour change techniques (BCTs) to address key barriers. Step 5: interventions were implemented. Step 6: the effectiveness of the project was evaluated using ongoing audit (see Fig. 1). Ethical approval and site specific governance was granted for this study by the local health district's Human Research Ethics Committee (reference: $15 / 103)$.

\section{Step 1: Multidisciplinary implementation team formation} Multidisciplinary implementation teams at the two hospitals were recruited through targeted invitation of known key staff and via expressions of interest. Teams were made up of people involved in the referral process and included medical and radiation oncologists, colorectal surgeons, anatomical pathologists, and genetic counsellors. Each team mapped the process of referral in their hospitals based on the typical patient journey. Process maps were sketched out on paper or by taking detailed notes with project investigators, then created electronically using Microsoft Visio software by the health services researchers. A narrative outline of the steps in the referral process was developed using exploratory questions (e.g., "and then what happens?") and refined and clarified over subsequent iterations. Seven face-to-face sessions were conducted between April and August 2015. Health services researchers facilitated all meetings and kept a project log to document project teams' assumptions and subjective views of the referral process, as well as discussions around barriers to referral and suggested solutions.

\section{Step 2 audits and defining the target behaviour}

The process maps defined key points where audit data could be collected, to both test assumptions of compliance with various steps, and to highlight problem areas on which to focus effort (e.g., number of people identified as having a high risk of LS who were not referred, or referred but chose not to attend FCC). Audits were timed to assess baseline, project initiation and intervention stages of the project for changes in referral numbers and processes. Data collected at each hospital were: patient's age, date of surgery, date of specimen receipt at pathology, date of report authorisation, date of supplementary report authorisation (if applicable), IHC results, BRAF V600E requests/results (if applicable), comments made by the reporting pathologist, presence and date of referral to FCC, acceptance by patient of referral, and attendance of the patient at the FCC. Referrals made to public genetic clinics elsewhere in the state were also noted. No clinical or family history was collected.

Audit data was collected by pathologists in the two hospitals searching their report databases using Systematised Nomenclature of Medicine (SNOMED) clinical terms to find reports on specimens coded as large, complex colorectal tumour specimens. IHC results and timing of reports were extracted from the retrieved reports. A genetic counsellor then matched patients to FCC clinic records by searching the statewide genetic service database. Records were then de-identified so whole numbers could be collated. Baseline data was collected retrospectively and covered the period May 2014-April 2015. The project initiation phase covered the months during which the project and the problem were discussed but no formal interventions had been started (May 2015-January 2016). The intervention phase covered the period February to November 2016. Numbers of patients flagged as at high risk were as per EviQ

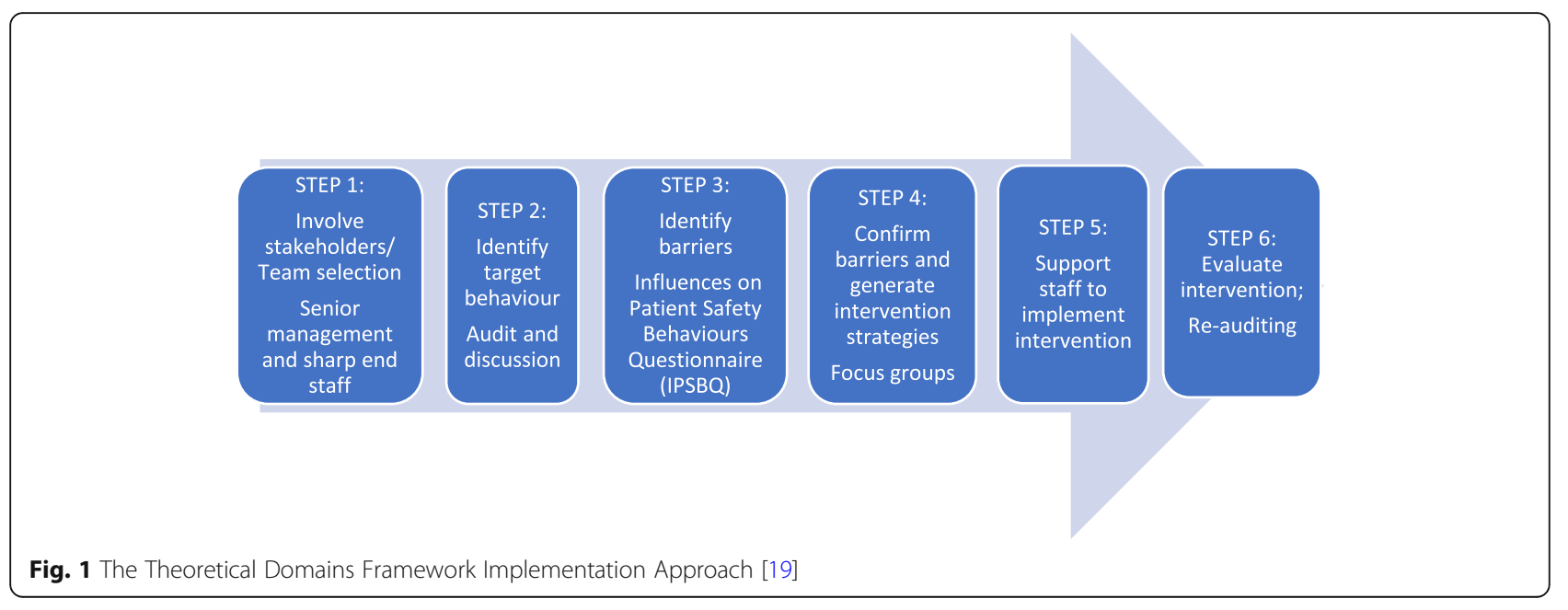


guidelines [20], and the number of those that were referred were graphed on a quarterly run chart.

The TDFI approach requires the team to define a target behaviour; that is, a behaviour that, if performed optimally, would result in the desired practice change. Results from the process mapping activities and the audit results were considered by an expert panel (oncologist, genetic counsellor and health services researchers) in order to define the target behaviour.

\section{Step 3 influences on patient safety Behaviours questionnaire (IPSBQ)}

The IPSBQ was used to determine barriers to achieving the target behaviour ("ensuring patients identified as having a high risk of Lynch syndrome are referred to genetic counselling") by considering each of 11 Theoretical Domain Framework (TDF) barriers (e.g. emotion, beliefs about consequences) [21]. The expert panel that defined the target behaviour also designed and formatted the IPSBQ to our context and purpose. The five minute $I P S B Q$ was offered in paper and online format to all staff involved in the management of patients with CRC. The top four barriers were determined by ranking the average scores for each domain (positively worded items were reverse-scored); the highest ranked scores represented the most significant barriers). We used the IPSBQ Data Entry Spreadsheet to compute these values [19]. ANOVAs were used to determine intergroup differences for Hospital A/Hospital B; those who refer/those that do not; those who were familiar with the guidelines for referral/those who were not. Significance was set at $\alpha<$ 0.05 . Barrier domains were tested for internal reliability across questions using Pearson correlations (one-tailed) for domains with two items (with values between $r=$ 0.15-0.50 being acceptable correlation [22, 23]) and Cronbach's alpha for the barrier with three items (with $\alpha>0.70$ being considered acceptable [24]).

\section{Step 4 focus groups and co-design of interventions}

Focus group participants were recruited using a purposive sampling approach to ensure a wide range of experience and viewpoints from staff involved in the management of people with CRC. We recruited via email and Colorectal Cancer Multi-Disciplinary Team meetings and offered separate interviews for people unable to schedule attendance at a group. Both types of session were digitally recorded or hand scribed and transcribed. The format of focus groups and interviews were the same, following a schedule of resources and questions (Additional file 1). This described the domains used to categorise the barriers, BCTs that could address each barrier domain, and examples of strategies identified in the literature that used appropriately matched BCTs e.g. [19, 25, 26].s For example, 'adding objects to the environment', identified as an effective BCT to address barriers related to the 'environmental context and resources' domain, has been previously operationalised by ensuring availability of $\mathrm{pH}$ paper to improve compliance with testing of aspirate as the first line check for correct positioning of nasogastric tubes [19]. Interventions discussed reflected the different roles of participants: those who were responsible for the decision to refer (treating oncologists and surgeons) and those in a supportive role (e.g. pathologists, geneticists, nurses).

In an iterative, bi-directional process, a table was constructed to clarify theoretical relationships [27-29]. Interventions generated by the focus groups and interviews were entered into this table alongside associated barrier domains. Log data of interventions that had been intuitively suggested were also added to the table and categorised according to the TDF domain being addressed. Results were triangulated with the IPSBQ data, and suggested interventions that did not address one of the four highest scoring barriers were removed. Final intervention strategies used to address key barriers emerged from synthesis of the intuitive and theory-based methods. Expert knowledge within the group (NT, DD, $\mathrm{JL}$ ) was used to match the appropriate BCT from Abraham's taxonomy [30] to each barrier.

\section{Step 5 implementation of the interventions}

Final versions of the proposed interventions were provided to hospital and department directors, and their authorisation and support for their implementation was formally sought. Health services researchers facilitated intervention development wherever possible.

\section{Step 6 monitoring of results}

Intervention phase audit results were compared to baseline and project initiation phase results. The interventions started in 2016 were assessed for level of completion at the end of the year and were treated as an intervention bundle when assessing their impact and outcomes.

\section{Results}

Step 1 implementation team selection and process mapping

Key health professionals at each oncology department were recruited to the multidisciplinary implementation teams: Hospital A $(n=8)$ and Hospital B $(n=11)$. The teams mapped the process of referral based on the patient journey. There were nine iterations of the map. The maps showed that IHC testing was done on all tumours removed from CRC patients (initiated by pathologists, but not an enforced policy) and that referral of high risk patients was reliant on correct interpretation of the ensuing report, and faxing of a paper referral form or letter to the FCC. Nine suggestions of interventions (intuitive interventions) were recorded in the project Log. 


\section{Step 2 audits}

The 12-month retrospective audit carried out by pathology registrars at each hospital found 71 and 113 patients having surgery for CRC at Hospital A and Hospital B respectively. Criteria for referral (following EviQ guidelines [20]) was 'any patient, of any age that had an abnormality on screening on one or more of the four mismatch repair genes (MLH1, PMS2, MSH2, MSH6)' (see Fig. 2). Supplementary testing (BRAF V600E) was not available at this time at either hospital pathology departments, so patients with MLH1/PMS2 abnormalities could only be referred to FCC, who then arranged supplementary testing through another pathology service. Hospital A had 11 patients with high risk results and referred four (36\%) and Hospital B, had 16 patients and referred two (13\%), showing that referral rates were suboptimal. Of the high risk patients who were not referred during this period, all were 60 years or older.

Baseline audit data from each hospital were added to simplified process maps, matched to the appropriate step. These maps were used as the main communication and discussion tool, and alongside the audit were used to establish the target behaviour, which was defined as: "ensuring that every patient at high risk of Lynch syndrome is referred to genetic counselling." The generic nature of the target behaviour reflected the differing roles and responsibilities of the staff involved in management of patients with CRC. This phrase completed the 23 barriers statements in the IPSBQ (see Table 1). Respondents indicated agreement or disagreement with the statements on a five point Likert scale ( $1=$ strongly agree to 5 = strongly disagree).

\section{Step 3 ISPBQ}

The three-minute IPSBQ was formatted to include the target behaviour and circulated to 71 healthcare professionals with a role in treatment or management of patients with CRC. The response rate was 51\% (36/71). The majority of respondents $(24 / 36)$ were medical officers with the rest from nursing (6), genetics (4) and administration (2). Sixteen (44\%) respondents indicated that they had responsibility for making referrals. Guidelines were familiar to $69 \%(25 / 36)$. Table 2 outlines respondents' details.

Missing values analysis (MVA) was undertaken on the full data set $(n=36)$ to highlight patterns of missing data and to replace them [31]. Little's MCAR test [32] was not significant $(p=0.23)$ indicating that data was missing completely at random. Therefore, estimation maximisation (EM) was used to impute missing values.

The highest scoring domain for barriers was 'environmental context and resources' [mean (M) 3.08, standard deviation ( $\mathrm{SD}) 0.84 \mathrm{]}$, followed by 'skills' $(\mathrm{M}=2.78, \mathrm{SD}=1.17)$, 'beliefs about capabilities' ( $\mathrm{M}=2.75, \mathrm{SD}=1.16)$, 'social influences' $(M=2.73, S D=0.76)$, and 'memory, attention and decision making' $(\mathrm{M}=2.61, \mathrm{SD}=0.84)$ (see Table 3 ).

Internal reliability was demonstrated by significant inter-item correlations and Cronbach's alpha for nine of the eleven domains; 'social/professional identity', and 'social influences' domains did not demonstrate internal reliability and were removed from the analysis (See Table 4).

One-way ANOVAs with Hospital, and then responsibility to refer as the grouping variable, showed no significant difference in any of the barriers. Additional file 2 shows details.

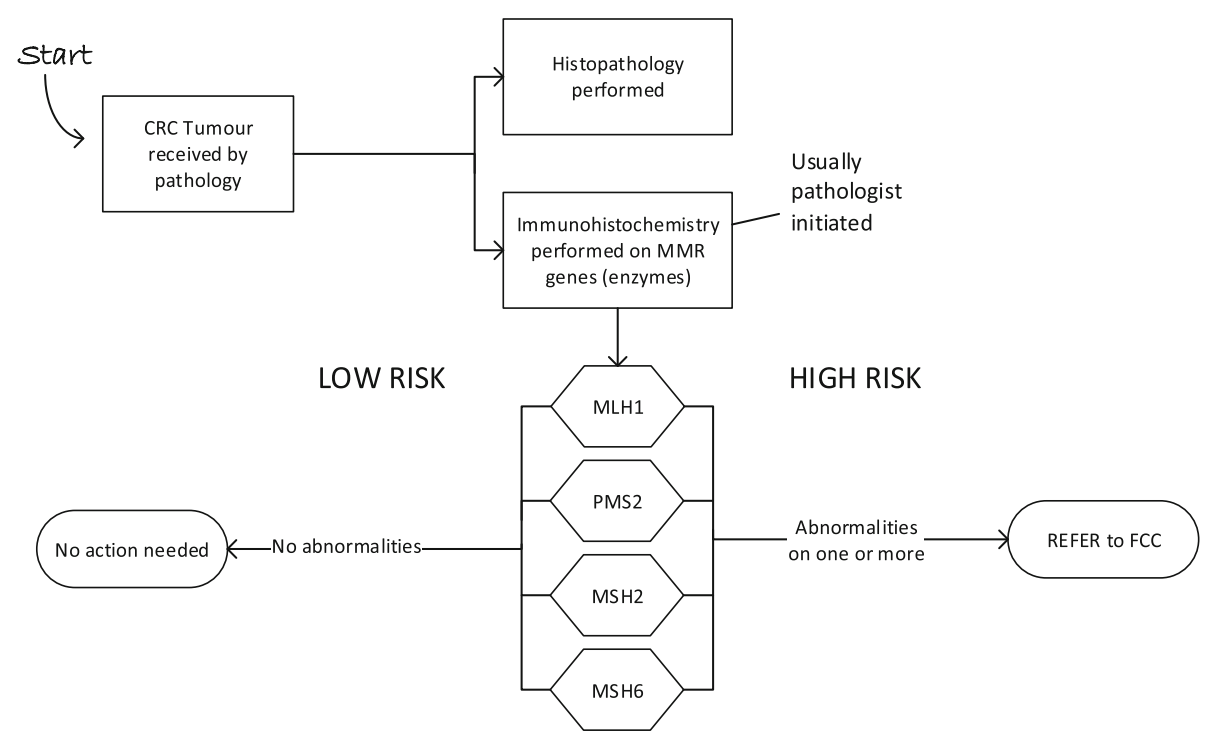

Fig. 2 Pathology flowchart at start of the project. All abnormalities found were referred directly to the Familial Cancer Clinic (FCC) 
Table 1 Statements in the Influences on Patient Safety Behaviours Questionnaire matched to the 11 domains of barriers to behaviour change [21]

\begin{tabular}{|c|c|c|}
\hline Domain & Questions & Target behaviour \\
\hline Knowledge & $\begin{array}{l}\text { I know what the guidelines say about the need to ... } \\
\text { I fully agree with the guidelines which instruct staff to ... }\end{array}$ & $\begin{array}{l}\text {.. ensure that every patient at high risk of Lynch } \\
\text { syndrome is referred to genetic counselling. }\end{array}$ \\
\hline Skills & $\begin{array}{l}\text { *Training is not offered to me regularly enough to ... } \\
\text { *Training is not adequate to ... }\end{array}$ & \\
\hline Social/profession role and identity & $\begin{array}{l}\text { *It isn't my responsibility to ... } \\
\text { I am clear about what my role should be in the process to ... }\end{array}$ & \\
\hline Beliefs about capabilities & $\begin{array}{l}\text { *I do not find it easy to ... } \\
\text { *I have previously encountered problems when trying to ... }\end{array}$ & \\
\hline Beliefs about consequences & $\begin{array}{l}\text { *It does not matter too much if I do not... } \\
\text { It will be bad for the patient if I do not ... }\end{array}$ & \\
\hline Motivation and goals & $\begin{array}{l}{ }^{*} \text { Emergencies and other priorities get in the way of me } \\
\text { being able to ... } \\
{ }^{*} \text { Other guidelines conflict with me being able to ... }\end{array}$ & \\
\hline $\begin{array}{l}\text { Memory, attention and decision-making } \\
\text { processes }\end{array}$ & $\begin{array}{l}\text { I habitually (or usually) ... } \\
\text { *There are justifiable reasons why often decide not to ... }\end{array}$ & \\
\hline Environmental context and resources & $\begin{array}{l}\text { *There is not a good enough system in place to ... } \\
\text { I have the necessary resources (e.g. correct/enough } \\
\text { equipment, staff, etc) to do ... } \\
\text { Verbal and written communication between staff is } \\
\text { clear enough for me to... }\end{array}$ & \\
\hline Social influences & $\begin{array}{l}\text { *Other staff don't seem to ... } \\
\text { My superiors would like me to ... }\end{array}$ & \\
\hline Emotion & $\begin{array}{l}\text { *I feel anxious if I think about having to ... } \\
\text { *I worry if I think about having to ... }\end{array}$ & \\
\hline Behavioural regulation/action planning & $\begin{array}{l}\text { *Plans in my head often get muddled when trying to ... } \\
\text { *Things are too unpredictable to make plans to ... }\end{array}$ & \\
\hline
\end{tabular}

Respondents indicated agreement or disagreement with the statements on a five point Likert scale: $(1=$ strongly agree to $5=$ strongly disagree) Note: Each question is ended by the stated target behaviour: "to ensure that every patient at high risk of Lynch syndrome is referred to genetic counselling." Questions marked with a *are stated as barriers and scores were reversed for analysis

\section{Step 4}

Focus groups and individual consultations involving nineteen key healthcare professionals confirmed that these five domains rang true and that 'environmental context and resources' represented the most significant barrier. Fifteen interventions were proposed by considering both emerging and theory-based results. Executive support was given for 12 of these interventions.

\section{Step 5}

Interventions were co-designed using appropriate BCTs matched to the identified barrier domains. For example, the 'memory, attention and decision making' domain may be addressed by the BCT of using 'prompts and cues' to focus attention, aid in decision making and streamline workflow. One team decided to add a pro forma at key follow-up consultations to review the patient's risk of hereditary cancer and to check if a referral had been made. This was a clear prompt to the team, making referral less likely to be overlooked. Table 5 lists details of barrier domains, barriers, proposed intuitive and theory based interventions, and matched BCTs. Also included are notes on how we operationalised the interventions.
Interventions were co-designed: clinicians brought experience, knowledge of existing work flow and tacit knowledge of processes to the table, while researchers advised on the best theory-based approaches and ways to study and map processes. Researchers also provided some practical support for interventions that were stalled or delayed due to lack of internal organisational capacity (e.g. by formatting new forms, liaising with data managers).

By mid-2016 there were enough results from ongoing audits to analyse trends in the referral patterns. An audit and feedback intervention was held with teams from each hospital at which a pathologist and a hereditary cancer specialist attended to answer questions. All patients under 50 years of age with abnormal IHC had been referred, often before their surgery, presumably on the basis of their family and clinical history. Patients over 50 years old with MLH1 and PMS2 abnormality were the main category not receiving referral.

\section{Step 6 monitoring of results}

The audits continued to December 2016. Two things were revealed by the monitoring audits. First, a clear change in practice for patients over 50 years old with 
Table 2 Details of the Influences on Patient Safety Barriers Questionnaire respondents

\begin{tabular}{|c|c|c|}
\hline Specialty or work area & $\mathrm{n}$ & $\%$ \\
\hline Medical oncology ${ }^{a}$ & 5 & 14 \\
\hline Surgery ${ }^{a}$ & 8 & 22 \\
\hline Pathology & 5 & 14 \\
\hline Familial Cancer & 6 & 17 \\
\hline Genetics Service admin & 1 & 3 \\
\hline Radiation oncology ${ }^{a}$ & 3 & 8 \\
\hline Oncology nursing & 6 & 17 \\
\hline Oncology admin & 1 & 3 \\
\hline Palliative care & 1 & 3 \\
\hline Years of experience & $n$ & $\%$ \\
\hline $0-1$ & 5 & 14 \\
\hline $2-5$ & 14 & 39 \\
\hline Over 5 & 17 & 47 \\
\hline Responsible to refer & $\mathrm{n}$ & $\%$ \\
\hline Yes & 16 & 44 \\
\hline No & 20 & 56 \\
\hline Familiarity with Guidelines & $\mathrm{n}$ & $\%$ \\
\hline Yes & 25 & 69 \\
\hline No & 11 & 31 \\
\hline
\end{tabular}
to refer

MLH1 and PMS2 abnormalities was now evident. Pathologists were consistently ordering supplementary testing for patients with MLH1 and PMS2 abnormalities (reflex testing). The results of this supplementary test (BRAF V600E) moves some patients from the high risk to the low risk group thus improving the ability to identify appropriate patients to refer. Responsibility for the initiation of this test had moved throughout the project from the FCC (at the start of the project), to the treating team (end 2015- mid 2016), to the pathologist (last quarter of 2016). The FCC could only initiate the test if a referral was first made. Figure 3 shows the new pathology process. As pathologists took over the role of initiating BRAF V600E testing, the proportion of appropriate patients recommended for this supplementary test went from $0 \%$ at Hospital A and 1\% at Hospital B at baseline (2014) to 67 and $88 \%$ by mid-2016. In the final quarter of 2016 , it was $100 \%$ at both hospitals. (Additional file 3 provides more details).

Second, the audits showed no change in rates of referral from baseline. Audit results for 2016 (for the 12 months after the interventions started) showed 77 and 126 patients undergoing surgery for CRC at
Table 3 Top ranked barrier domains for the different groups of respondents

\begin{tabular}{|c|c|c|}
\hline Barrier Domain & Mean score & Standard deviation \\
\hline \multicolumn{3}{|l|}{ All respondents $n=36$} \\
\hline $\begin{array}{l}\text { Environmental context } \\
\text { and resources }\end{array}$ & 3.08 & 0.84 \\
\hline Skills & 2.78 & 1.17 \\
\hline Beliefs about capabilities & 2.75 & 1.16 \\
\hline $\begin{array}{l}\text { Memory, attention and } \\
\text { decision-making }\end{array}$ & 2.61 & 0.84 \\
\hline \multicolumn{3}{|l|}{ Responsible for referral $n=16$} \\
\hline $\begin{array}{l}\text { Environmental context } \\
\text { and resources }\end{array}$ & 3.00 & 0.88 \\
\hline Beliefs about capabilities & 2.76 & 1.19 \\
\hline $\begin{array}{l}\text { Memory, attention and } \\
\text { decision-making }\end{array}$ & 2.50 & 0.80 \\
\hline Skills & 2.24 & 0.90 \\
\hline \multicolumn{3}{|l|}{ Not responsible to refer $n=20$} \\
\hline Skills & 3.16 & 1.19 \\
\hline $\begin{array}{l}\text { Environmental context } \\
\text { and resources }\end{array}$ & 3.12 & 0.79 \\
\hline $\begin{array}{l}\text { Memory, attention and } \\
\text { decision-making }\end{array}$ & 2.69 & 0.89 \\
\hline Beliefs about capabilities & 2.64 & 1.04 \\
\hline \multicolumn{3}{|l|}{$\begin{array}{l}\text { Familiar with referral guidelines } \\
n=25\end{array}$} \\
\hline $\begin{array}{l}\text { Environmental context and } \\
\text { resources }\end{array}$ & 3.06 & 0.86 \\
\hline Beliefs about capabilities & 2.63 & 1.20 \\
\hline $\begin{array}{l}\text { Memory, attention and } \\
\text { decision-making }\end{array}$ & 2.57 & 0.94 \\
\hline Skills & 2.55 & 1.07 \\
\hline \multicolumn{3}{|l|}{$\begin{array}{l}\text { Not familiar with referral } \\
\text { guidelines } n=11\end{array}$} \\
\hline Skills & 3.22 & 1.24 \\
\hline $\begin{array}{l}\text { Environmental context } \\
\text { and resources }\end{array}$ & 3.09 & 0.75 \\
\hline Beliefs about capabilities & 2.84 & 0.82 \\
\hline Professional identity & 2.74 & 0.72 \\
\hline $\begin{array}{l}\text { Memory, attention } \\
\text { and decision-making }\end{array}$ & 2.68 & 0.60 \\
\hline
\end{tabular}

Hospital A and B respectively. Sixteen (Hospital A) and 20 (Hospital B) patients had an abnormality on one or more of the four mismatch repair genes indicating a high risk of LS. Two patients at Hospital A and one at Hospital B had results indicating a direct referral to genetics (abnormality on MSH6), only one of whom was referred. Supplementary testing for BRAF V600E was required for 12 patients (Hospital A) and 16 patients (Hospital B). Auditors were unable to see results of some 
Table 4 Inter-item reliability scores for barriers

\begin{tabular}{lllll}
\hline Domain & $\begin{array}{l}\text { Number of } \\
\text { questions }\end{array}$ & $\begin{array}{l}\text { Pearson's } \\
\text { correlation }\end{array}$ & $\begin{array}{l}\text { Significance } \\
\text { (one-tailed) }\end{array}$ & $\begin{array}{l}\text { Cronbach's } \\
\text { Alpha }\end{array}$ \\
\hline Knowledge & 2 & $\mathbf{0 . 4 4}$ & $\mathbf{0 . 0 0}$ & \\
$\begin{array}{l}\text { Skills } \\
\text { Social/profession }\end{array}$ & 2 & $\mathbf{0 . 6 1}$ & $\mathbf{0 . 0 0}$ & \\
role and identity & 2 & 0.01 & 0.28 & \\
$\begin{array}{l}\text { Beliefs about } \\
\text { capabilities }\end{array}$ & 2 & $\mathbf{0 . 3 6}$ & $\mathbf{0 . 0 2}$ & \\
$\begin{array}{l}\text { Beliefs about } \\
\text { consequences }\end{array}$ & 2 & $\mathbf{0 . 3 9}$ & $\mathbf{0 . 0 1}$ \\
$\begin{array}{l}\text { Motivation and } \\
\text { goals }\end{array}$ & 2 & $\mathbf{0 . 4 4}$ & $\mathbf{0 . 0 1}$ \\
$\begin{array}{l}\text { Memory, attention } \\
\text { and decision-making }\end{array}$ & 2 & $\mathbf{0 . 3 4}$ & $\mathbf{0 . 0 2}$ & \\
$\begin{array}{l}\text { Environmental } \\
\text { context and resources }\end{array}$ & 3 & & $\mathbf{0 . 7 0}$ \\
$\begin{array}{l}\text { Social influences } \\
\text { Emotion }\end{array}$ & 2 & 0.07 & 0.35 \\
$\begin{array}{l}\text { Behavioural } \\
\text { regulation/action } \\
\text { planning }\end{array}$ & 2 & $\mathbf{0 . 6 4}$ & $\mathbf{0 . 0 0}$ \\
\hline
\end{tabular}

of the tests that were outsourced to other pathology services (by pathologists or treating team) early in the year, but of those that were available, seven and four patients respectively were found to be low risk. Of the two patients at Hospital A and three at Hospital B with negative BRAF V600E results indicating the need for a referral to the genetic service for LS assessment, only one of these five people was referred. All audit results are shown in Table 6.

\section{Discussion}

We used the TDFI approach aiming to increase the referral rate of patients with a high risk of LS into the FCC. The six steps of the TDFI approach generated high quality data: establishing there was a problem, defining barriers to change and guiding the design of interventions to address these barriers. Simplified process maps cross matched to data from the audits were shown to be highly engaging to the majority of health professionals. The maps highlighted that referrals are complex, involving many more people than the clinician filling out the actual form. Barrier data also indicated that the IHC test results were sometimes challenging to interpret and arrived in the often-fraught post-operative period, meaning referrals were often deferred.

While we were unable to demonstrate an overall increase in referrals, we can show behaviour change in earlier parts of the LS screening process. More specifically, by the end of the project, BRAF V600E testing was initiated for $100 \%$ of the patients who required it. Given that the audit and feedback intervention strategy highlighted that some clinicians believed most patients over 60 would have somatic (non-hereditary) tumours and so deemed referral to be inappropriate, this supplementary test is valuable in clarifying appropriate patients to refer for genetic testing. Further, test reports have been clarified by both pathology departments meaning results are easier to interpret; genetic specialists, counsellors, oncologists and surgeons have collaborated to introduce regular education sessions for rotating and new staff; referral forms have been added to the electronic patient record - removing the need to hunt down elusive paper referrals or write individual letters. Therefore, it may be that more time is required for these new pre-referral processes to embed into the system before the desired front end clinician behaviour change - i.e., referral of appropriate patients for genetic testing - is demonstrated. This has been seen in other implementation projects e.g. [33].

One other possible explanation for the lack of improvement in appropriate referrals may be related to our target behaviour definition: "to ensure that patients at high risk of LS are referred to the FCC." Only the medical treating team (medical and radiation oncologists and CR surgeons) were able to make a referral yet this project promoted the view that all staff managing patients with CRC had a responsibility to ensure it happened. The target behaviour, therefore was deliberately broad to encompass the multidisciplinary team and their various roles in the referral process. For example, a pathologist might interpret "ensuring referral" to mean that their reporting should be accurate and clear, a nurse that they are alert to patient disclosures of relevant family history, or an MDT coordinator that relevant information is available for the case conference. This was useful as it meant a single version of the IPSBQ could be used for everyone, and it stimulated all team members to consider their individual role. However, whilst we saw pathologist test-ordering and results-reporting behaviour changes, for the medical team that made the actual referrals, there was perhaps not a clear enough statement of action. "Make a referral" seems a very straightforward behaviour, but for the medical team it was a multistep process (interpreting test results correctly, discussing with the patient, finding a referral form, faxing it, etc) reliant on other members of the department doing their part (e.g., pathologists reporting clearly). It is therefore possible that barriers to each of these more defined behaviours that make up referral could have been more targeted. Separate target behaviours for different clinical groups (e.g., relating to clearer reporting for pathologists, documenting patient disclosures of relevant family history for nurses, ensuring relevant patient family history information is provided to clinicians in MDT 


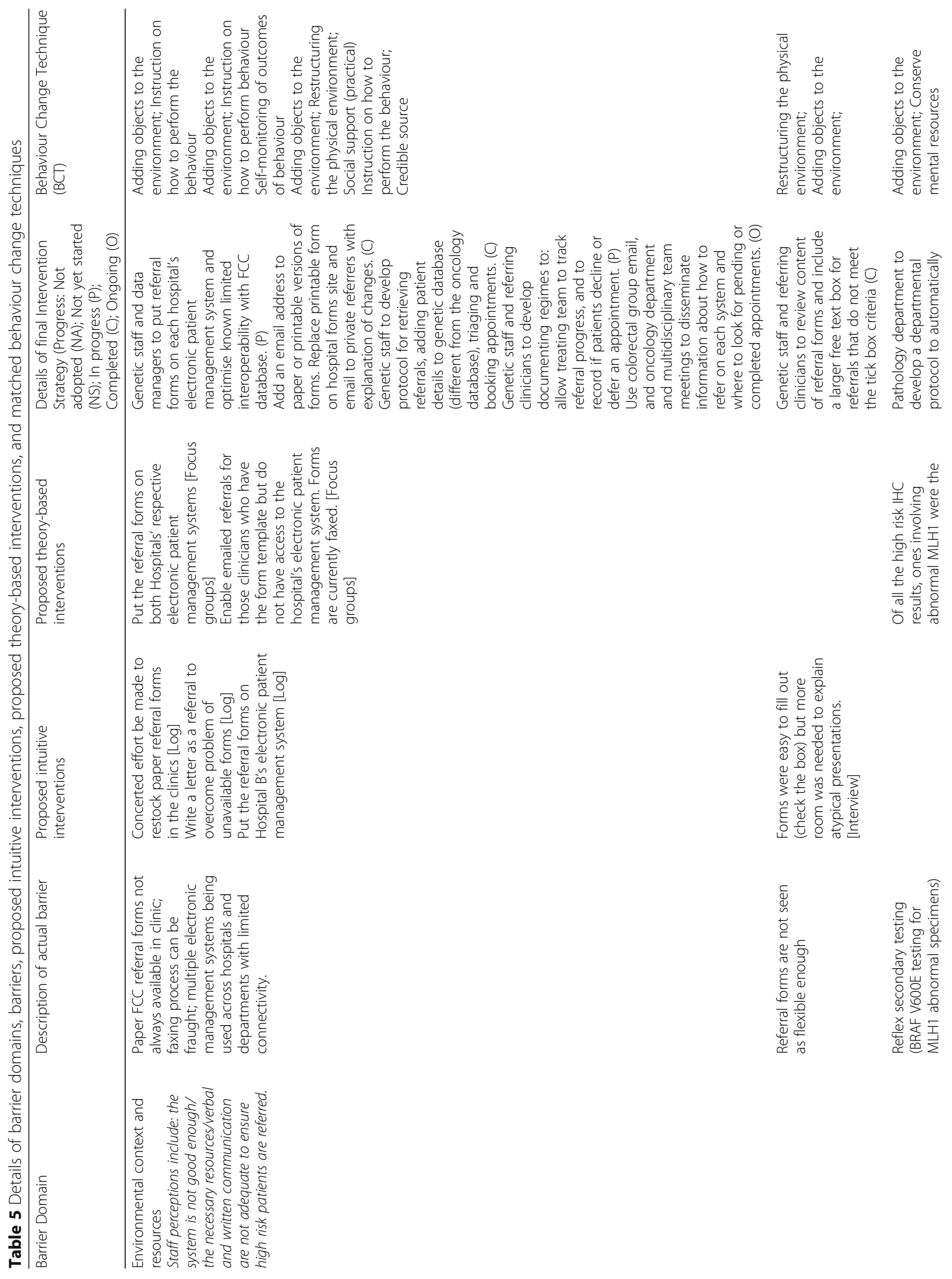




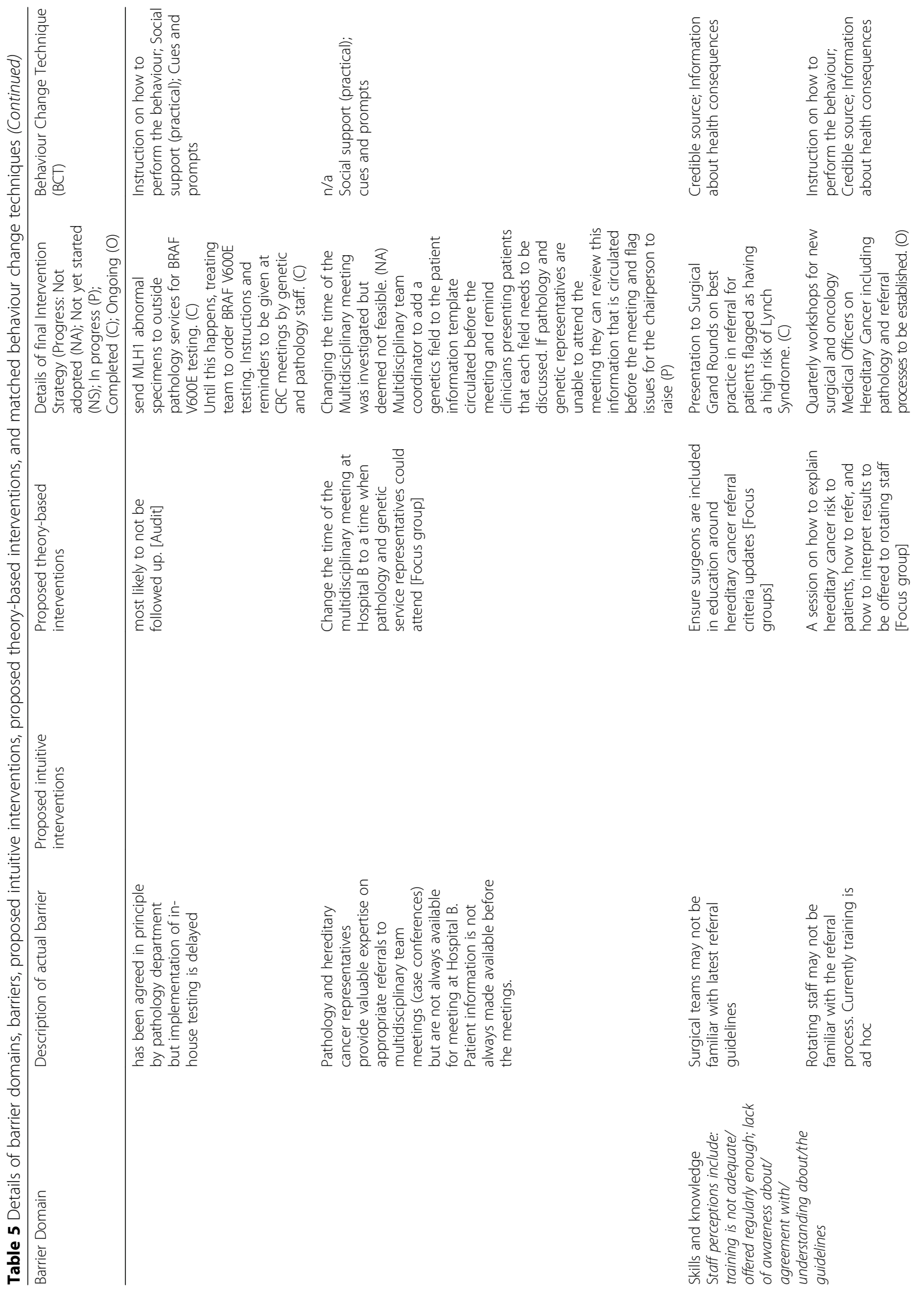




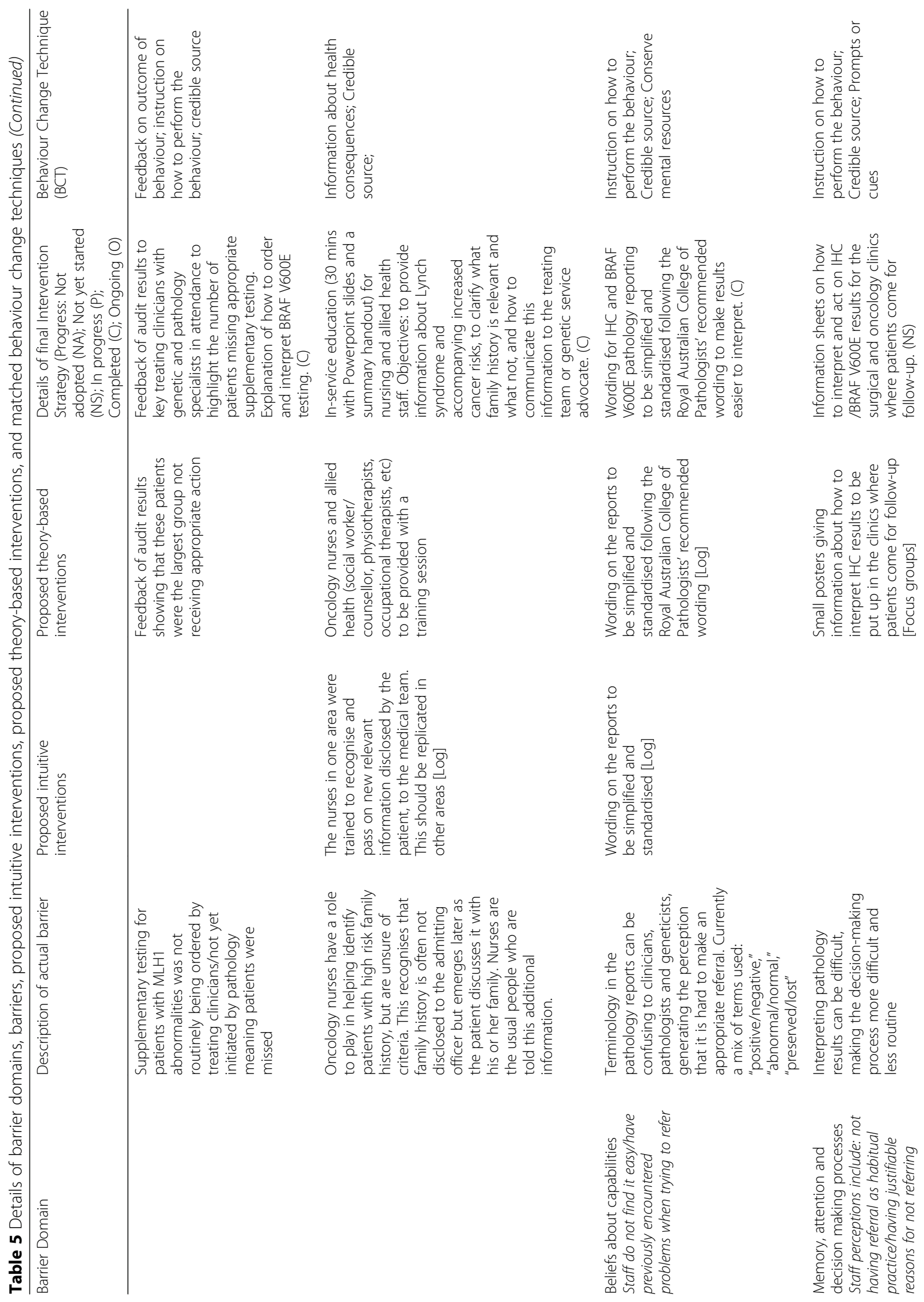




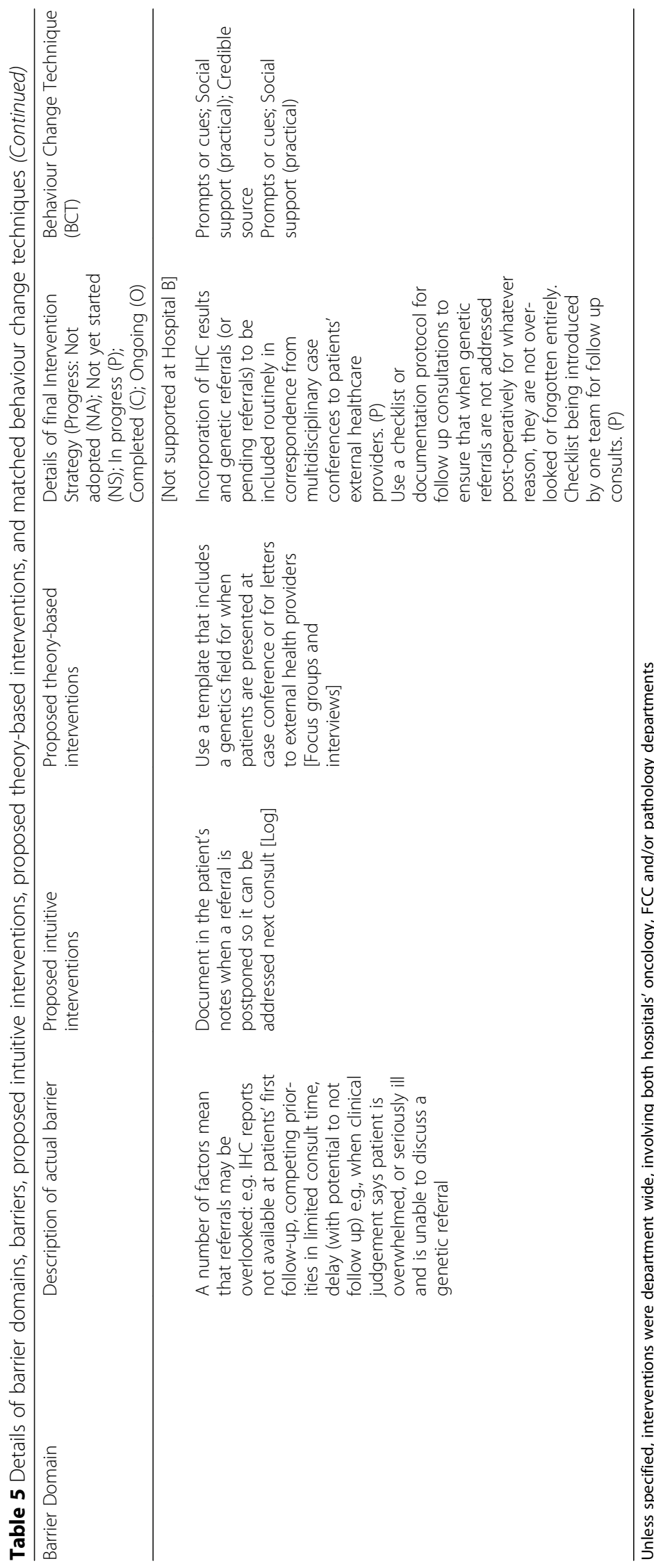




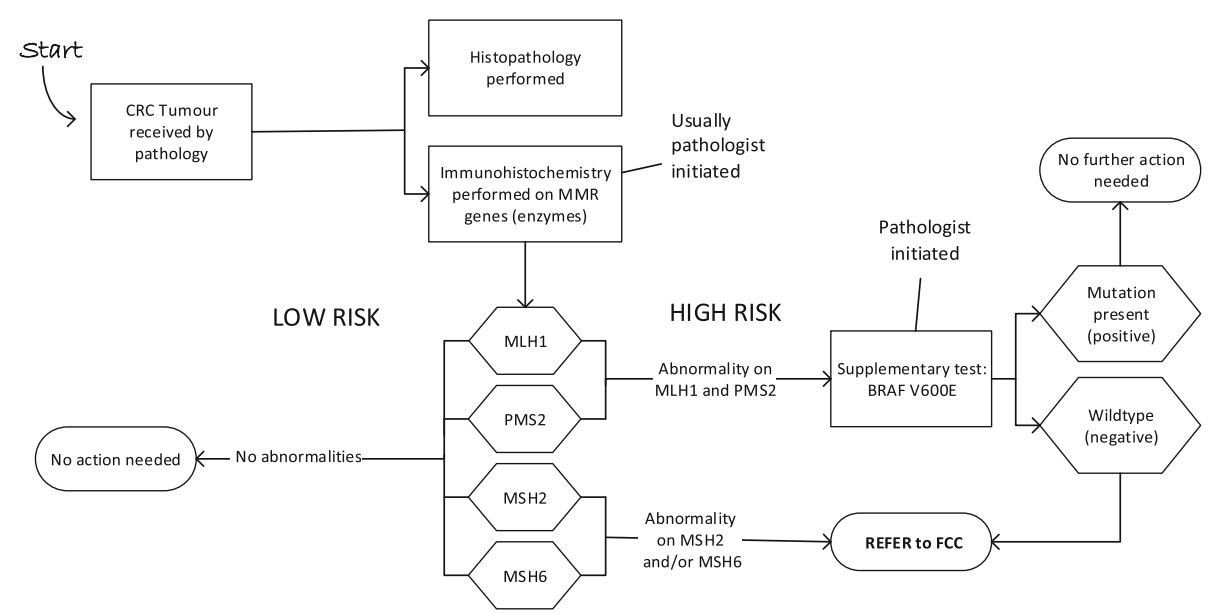

Fig. 3 Pathology flowchart at end of the project. All patients with abnormalities on MSH2 and/or MSH6 were referred directly to the Familial Cancer Clinic (FCC), while patients with MLH1 and PMS2 abnormalities had a pathologist initiated supplementary test on the same tumour sample to determine the likelihood of a germline or somatic tumour

meetings for administrators, and using all available information to ensure all appropriate patients are referred into FCC for clinicians), may have focussed action and led to more effective intervention design [34].

Some interventions were quickly implemented (e.g., education sessions by genetic staff, clearer wording of test reports by pathologists), while others were more difficult (adding referral forms to the electronic patient management system and working out how to deal with interoperability of software systems). Michie and colleagues ([35], p. 250) recommend applying the APEASE criteria to assess potential interventions. APEASE stands for affordability, practicality, effectiveness, acceptability, side-effects/safety and equity and is a way of screening out less feasible solutions. In hindsight, use of the APEASE criteria to assess for their affordability and practicality might have allowed us to identify key but most feasible interventions.

System level factors beyond the control of the project team caused lengthy delays in implementation of some of the interventions (e.g. implementation of a new state-wide genetic database delayed introduction of new referral processes; physical relocation to a new oncology building delayed some education sessions; changes to

Table 6 Raw data from the audits carried out by pathology and genetics on referral to the Familial Cancer Clinic

\begin{tabular}{|c|c|c|c|c|c|c|c|}
\hline \multirow[b]{2}{*}{ Quarter } & \multirow[b]{2}{*}{ Project stage } & \multicolumn{3}{|l|}{ Hospital A } & \multicolumn{3}{|l|}{ Hospital B } \\
\hline & & $\begin{array}{l}\text { No. patients } \\
\text { screened }\end{array}$ & $\begin{array}{l}\text { No. patients } \\
\text { requiring referral }\end{array}$ & $\begin{array}{l}\text { No. patients } \\
\text { referred }\end{array}$ & $\begin{array}{l}\text { No. of patients } \\
\text { screened }\end{array}$ & $\begin{array}{l}\text { No. patients } \\
\text { requiring referral }\end{array}$ & $\begin{array}{l}\text { No. patients } \\
\text { referred }\end{array}$ \\
\hline Apr-June 14 & Baseline & 17 & 1 & 1 & 19 & 2 & 0 \\
\hline Jul-Sept 14 & & 16 & 0 & 0 & 34 & 5 & 0 \\
\hline Oct-Dec 14 & & 19 & 1 & 0 & 34 & 3 & 1 \\
\hline \multirow[t]{2}{*}{ Jan-Mar 15} & & 19 & 3 & 3 & 26 & 2 & 0 \\
\hline & & 71 & 5 & $4(80 \%)$ & 113 & 12 & $1(8.3 \%)$ \\
\hline Apr-June 15 & Project starts & 14 & 0 & 0 & 42 & 4 & 2 \\
\hline Jul-Sept 15 & & 23 & 5 & 0 & 33 & 3 & 0 \\
\hline \multirow[t]{2}{*}{ Oct-Dec 15} & & 27 & 7 & 7 & 27 & 4 & 2 \\
\hline & & 64 & 12 & 7 (58\%) & 102 & 11 & $4(36 \%)$ \\
\hline Jan-Mar 16 & Interventions start & 23 & 4 & 1 & 24 & 2 & 0 \\
\hline Apr-June 16 & & 19 & 3 & 3 & 23 & 3 & 0 \\
\hline Jul-Sept 16 & & 17 & 2 & 1 & 45 & 3 & 1 \\
\hline \multirow[t]{2}{*}{ Oct-Dec 16} & & 18 & 2 & 1 & 34 & 3 & 0 \\
\hline & & 77 & 11 & $6(55 \%)$ & 126 & 11 & $1(9 \%)$ \\
\hline
\end{tabular}


the pathology departments' database delayed audits). It is therefore also possible these delays have slowed the impact of interventions. An audit of referral rates of patients at high risk after a further 12 months has elapsed would be useful to determine whether such system changes had delayed results.

It is possible that some of the TDF barrier domains [21] may not have been addressed adequately with interventions. For example, 'social/professional role and identity' was identified as a barrier and several theoretically sound interventions were suggested to overcome this (i.e., pathologists to refer/notify oncologists of any high risk LS results; a senior oncology nurse be tasked to review all pathology results and be authorized to refer), but these were not approved by senior management. Furthermore, whilst we have been transparent about the intervention development process, the difficulties faced with attempting to work with healthcare professionals to develop theory-based interventions is a difficult task due mainly to competing pressures of service delivery. This means that the quality of the interventions may have been jeopardised, resulting in less of an impact on behaviour. This approach also makes effects difficult to unpick. Nonetheless co-design is an important factor contributing to the success of implementation activities [36, 37].

We noted early in the project that clinicians were aware of a number of different guidelines for identifying patients at high risk of LS $[38,39]$. Some of these state that only patients under 50 years of age should be considered while others, such as the EviQ guidelines (see https://www.eviq.org.au/AboutUs.aspx) used at our hospitals, state "at any age" [20]. We understand this lack of consistency may have contributed to lower referral rates in the over 60 age group and would recommend that this be clarified. A consistent message is being given in the education sessions.

Change in clinical practice settings often takes a long time, especially with low incidence conditions such as Lynch syndrome. Our various attempts at changing individual health professional's behaviour has had no impact on referral rates so far. The process is undoubtedly improved with the introduction of reflex testing but that crucial next step of appropriate review and response to these results by the treating oncologist or surgeon is not yet happening. We speculate (from anecdotal sources) that barriers to this may be that they are not actively looking for the results (since the reflex test is pathologist initiated), and if the results are reviewed, they are unfamiliar with what the results mean.

There is evidence from the US [40] that high risk LS referrals are increased in hospitals where a clinician referral is not required and genetic counsellors have direct access to genetic test results and clinical information. Again, this is worth considering implementing in other countries where the strategy is absent. Frequencies of high risk cases are low (1-2 a month) making it more feasible, although longer term solutions will need to be discussed. Genetic counsellors do not have unlimited capacity so strategies to address this should be considered.

Hospital A's final referral rate appeared to improve more than Hospital B, however the numbers are of patients flagged at high risk are too low to draw any meaningful, statistical conclusions. We can say generally, that we observed some very engaged teams and some less interested teams at both hospitals, and we know that some teams did not have any patients identified as high risk. Others reported a reluctance to refer when patients were extremely ill, or if they died but we have no means of linking teams with individual cases.

Limitations of the study are related to the low numbers of patients affected by LS. This meant that we could not show statistically a change in the practice of referral in the time frame. Another limitation is that although we coded intuitive interventions and theory guided interventions, it is difficult to unpick mechanisms of action (or lack thereof). Process evaluation would be helpful in answering some of these questions [41].

The conventional wisdom in implementation science is to choose a high incidence problem as a target for change. Table 6 shows that the incidence of LS is low which makes new practices difficult to routinize (as they are undertaken infrequently) and change takes longer to spread to all clinicians. However, LS identification is a problem we need to solve. The health system is likely to be overwhelmed with low incidence problems as genomic testing becomes mainstream and reveals more and more low incidence hereditary cancers or syndromes. Each will require identification, appropriate care, and risk management. It is crucial for health researchers to test methods and provide health systems with generalizable solutions to address this problem so multidisciplinary teams can work together to streamline their response to this enhanced diagnostic ability.

\section{Conclusion}

We were unable to demonstrate an overall increase in referrals, but we now have a deeper understanding of the various barriers to referral and have increased our knowledge of how to approach low frequency conditions. While referral rates did not change, the entire process from a systems perspective has been streamlined. This has enabled more accurate identification of appropriate patients and has set up an optimal context for consideration of an automatic referral system. The TDFI approach is currently being evaluated (in a separate project) to formally test whether the methods we used are acceptable, feasible and appropriate in a hereditary cancer setting. 


\section{Additional files}

Additional file 1: Barrier Domains and examples of matched behaviour change techniques (BCT) for use in Focus groups. (DOCX 23 kb)

Additional file 2: Oneway ANOVAs (Table A2) with Hospital as the grouping variable showed no significant difference in any of the barriers. Grouping by responsibility to refer/not responsible to refer showed a difference in the 'skills' domain only $(p=0.01)$. Grouping by familiarity with the guidelines for referral/those who were not familiar showed all the domains were significantly different except for 'beliefs about capabilities' (0.14). (DOCX 16 kb)

Additional file 3: The effect of age on appropriate supplementary testing. (DOCX $27 \mathrm{~kb}$ )

\section{Abbreviations}

CRC: Colorectal cancer; FCC: Family Cancer Clinic; IHC: Immunohistochemistry; IPSBQ: Influences on Patient Safety Behaviours Questionnaire; LS: Lynch syndrome; MMR: Mismatch Repair Deficiency; NSW: New South Wales; TDFI: Theoretical Domains Framework Implementation

\section{Acknowledgements}

We thank all 70 participants at Hospital A and B, Lynch Syndrome Australia and the TCRN Consumer Advisory Council.

\section{Funding}

The project team acknowledges funding by a Cancer Challenge of the Year 2015 grant from the NSW Cancer Institute, administered through the Translational Cancer Research Network. NT receives no financial gain from use of her intellectual property in the TDFI training package. JB's work and this project is funded in part by National Health and Medical Research Council Program Grant APP1054146. Cancer Institute NSW did not have any role in the design of the study and collection, analysis, and interpretation of data and in writing the manuscript.

\section{Availability of data and materials}

The focus group schedule to guide discussion for intervention design is provided in Additional file 1. The Influences on Patient Safety Behaviours Questionnaire available on request from the author. The audit datasets collected and analysed during the current study are available from the corresponding author on reasonable request.

\section{Authors' contributions}

NT conceived and developed the protocol. JCL, NT wrote the manuscript and JCL, DD, RW, ES, SON, EE, JB, RR, KCPT, SRT, MC and NT designed the audit, selected indicators, co-designed and implemented interventions, collected data, and analysed results. JL, DD, RW, ES, SON, EE, JB, RR, KCPT, SRT, JB, MC, and NT critically reviewed the manuscript over several versions and approved the final manuscript. JB also provided access to resources and academic oversight.

\section{Ethics approval and consent to participate}

Ethical approval and site-specific governance was granted for this study by the South Eastern Sydney Local Health District Human Research Ethics Committee (reference: 15/103). All focus group and interview participants received a Participant Information Sheet and gave written consent for their de-identified comments to be used in wider reporting.

\section{Consent for publication}

Not applicable.

\section{Competing interests}

The authors declare that they have no competing interests.

\section{Publisher's Note}

Springer Nature remains neutral with regard to jurisdictional claims in published maps and institutional affiliations.

\section{Author details}

'Centre for Healthcare Resilience and Implementation Science, Australian Institute of Health Innovation, Faculty of Medicine and Health, Macquarie
University, Sydney, NSW, Australia. ${ }^{2}$ Faculty of Health, University of Technology, Sydney, Australia. ${ }^{3}$ Nelune Comprehensive Cancer Centre, Prince of Wales Hospital, Randwick, NSW, Australia. ${ }^{4}$ Prince of Wales Clinical School, Faculty of Medicine, University of New South Wales, Sydney, NSW, Australia. ${ }^{5}$ NSW Pathology (SEALS), Prince of Wales Hospital, Randwick, NSW, Australia. ${ }^{6}$ School of Business, University of NSW, Campbell, ACT, Australia. ${ }^{7}$ NSW Pathology (SEALS), St George Hospital, Kogarah, NSW, Australia. ${ }^{8}$ Anatomical Pathology, Royal Prince Alfred Hospital, Camperdown, NSW, Australia. ${ }^{9} \mathrm{St}$ George and Sutherland Clinical School, University of New South Wales, Randwick, NSW, Australia. ${ }^{10}$ Cancer Council NSW, Woolloomooloo, NSW, Australia.

Received: 20 February 2018 Accepted: 26 October 2018 Published online: 28 November 2018

\section{References}

1. Woolf $\mathrm{SH}$. The meaning of translational research and why it matters. JAMA. 2008:299(2):211-3

2. Roberts MC, Kennedy AE, Chambers DA, Khoury MJ. The current state of implementation science in genomic medicine: opportunities for improvement. Genetics In Medicine. 2017;19:858.

3. Dowty JG, Win AK, Buchanan DD, Lindor NM, Macrae FA, Clendenning M, et al. Cancer risks for MLH1 and MSH2 mutation carriers. Hum Mutat. 2013; 34(3):490-7.

4. Vasen H, Blanco I, Aktan-Collan K, et al. Revised guidelines for the clinicial management of lynch syndrome (HNPCC): recommendations by a group of Europeans experts. Gut. 2013;62(6):812-23.

5. Barrow P, Khan M, Lalloo F, Evans DG, Hill J. Systematic review of the impact of registration and screening on colorectal cancer incidence and mortality in familial adenomatous polyposis and lynch syndrome. $\mathrm{Br} \mathrm{J}$ Med Surg. 2013;100(13):1719-31.

6. Frayling I, Ward R. Should we consider introducing systematic screening for lynch syndrome? Cancer Forum. 2014;38(3):229-32.

7. EviQ. Colorectal cancer referral guidelines v.4; accessed April 2016. Available from: https:/www.eviq.org.au/Protocol/tabid/66/id/657/defid/11863/Default.aspx. Accessed Jan 2018

8. Morris S, Rice T, O'Neill S, Raets E, Fairbank B. Misdiagnosed, misunderstood and missing out: Iynch syndrome. Australia's untold health story. A report by lynch syndrome Australia - 2017. Brisbane: Lynch Syndrome Australia; 2017.

9. Tan Y, McGaughran J, Ferguson K, Walsh M, Buchanan D, Young J, et al. Improving identification of lynch syndrome patients: a comparison of research data with clinical records. Int J Cancer. 2013;132(12):2876-83.

10. Wong C, Gibbs P, Johns J, Jones I, Faragher I, Lynch E, et al. Value of database linkage: are patients at risk of familial colorectal cancer being referred for genetic counselling and testing? Intern Med J. 2008;38(5):328-33.

11. Grover S, Stoffel EM, Bussone L, Tschoegl E, Syngal S. Physician assessment of family cancer history and referral for genetic evaluation in colorectal cancer patients. Clin Gastroenterol Hepatol. 2004;2(9):813-9.

12. Pujol P, Lyonnet DS, Frebourg T, Blin J, Picot MC, Lasset C, et al. Lack of referral for genetic counseling and testing in BRCA1/2 and lynch syndromes: a nationwide study based on 240,134 consultations and 134,652 genetic tests. Breast Cancer Res Treat. 2013;141(1):135-44.

13. Singh H, Schiesser R, Anand G, Richardson PA, El-Serag HB. Underdiagnosis of lynch syndrome involves more than family history criteria. Clin Gastroenterol Hepatol. 2010;8(6):523-9.

14. Grol R, Grimshaw J. From best evidence to best practice: effective implementation of change in patients' care. Lancet. 2003;362(9391):1225-30.

15. Davidoff F, Dixon-Woods M, Leviton L, Michie S. Demystifying theory and its use in improvement. BMJ Qual Saf. 2015;24(3):228-238.

16. Taylor N, Lawton R, Moore S, Craig J, Slater B, Cracknell A, et al. Collaborating with front-line healthcare professionals: the clinical and cost effectiveness of a theory based approach to the implementation of a national guideline. BMC Health Serv Res. 2014;14(1):1-10.

17. Taylor N, Long JC, Debono D, Williams R, Salisbury E, O'Neill S, et al. Achieving behaviour change for detection and management of lynch syndrome using the theoretical domains framework implementation (TDFI) approach: a study protocol. BMC Health Serv Res. 2016;16:89.

18. Taylor N, Parveen S, Robins V, Slater B, Lawton R. Development and initial validation of the influences on patient safety Behaviours questionnaire. Implement Sci. 2013;8(1):81. 
19. Taylor N, Lawton R, Slater B, Foy R. The demonstration of a theory-based approach to the design of localized patient safety interventions. Implement Sci. 2013;8(1):123.

20. EviQ. Genetic testing for hereditary mutations in the mismatch repair genes (MMR-genes) 2016. Available from: https://www.eviq.org.au/Protocol/tabid/ 66/id/619/defid/11004/Default.aspx?popup=1. Accessed Jan 2018.

21. Michie S, Johnston M, Abraham C, Lawton R, Parker D, Walker A. Making psychological theory useful for implementing evidence based practice: a consensus approach. Qual Saf Health Care. 2005;14(1):26-33.

22. Briggs $S$, Cheek J. The role of factor analysis in the evaluation of personality scales. J Pers. 1986;54:106-48.

23. Clark L, Watson D. Constructing validity: basic issues in objective scale development. Psychol Assess. 1995;7:309-19.

24. George D, Mallery P. SPSS for Windows step by step: A simple guide and reference. 11.0 update. 4th ed. Boston: Allyn \& Bacon; 2003

25. Backman R, Foy R, Michael BD, Defres S, Kneen R, Solomon T. The development of an intervention to promote adherence to national guidelines for suspected viral encephalitis. Implement Sci. 2015;10:37.

26. French SD, Green SE, O'Connor DA, McKenzie JE, Francis JJ, Michie S, et al. Developing theory-informed behaviour change interventions to implement evidence into practice: a systematic approach using the theoretical domains framework. Implement Sci. 2012;7(1):1-8.

27. Michie S, Johnston M, Francis J, Hardeman W, Eccles M. From theory to intervention: mapping theoretically derived behavioural determinants to behaviour change techniques. Appl Psychol. 2008;57(4):660-80.

28. Cane J, Richardson M, Johnston M, Ladha R, Michie S. From lists of behaviour change techniques (BCTs) to structured hierarchies: comparison of two methods of developing a hierarchy of BCTs. Br J Health Psychol. 2015;20(1):130-50

29. Yorkshire Quality and Safety Research Group. ABC for patient safety. Bradford: Improvement Academy, Yorkshire \& Humber Academic Health Science Network partners; 2013.

30. Abraham C, Michie S. A taxonomy of behavior change techniques used in interventions. Health Psychol. 2008;27(3):379-87.

31. Tabachnick B, Fidell L. Using multivariate statistics. 5th ed. Boston: Pearson Education, Inc.; 2007.

32. Little R. A test of missing completely at random for multivariate data with missing data. J Am Stat Assoc. 1988;83:1198-202.

33. Rotteau L, Webster F, Salkeld E, Hellings C, Guttmann A, Vermeulen M, et al. Ontario's emergency department process improvement program: the experience of implementation. Acad Emerg Med. 2015;22(6):720-9.

34. Atkins L, Hunkeler EM, Jensen CD, Michie S, Lee JK, Doubeni CA, et al. Factors influencing variation in physician adenoma detection rates: a theory-based approach. Gastrointest Endosc. 2016;83(3):617-26.e2.

35. Michie $S$, Atkins $L$, West $R$. The behaviour change wheel: a guide to designing interventions. Great Britain: Silverback Publishing; 2014.

36. Greenfield D, Nugus P, Travaglia J, Braithwaite J. Factors that shape the development of interprofessional improvement initiatives in health organisations. BMJ Qual Saf. 2011;20(4):332-7.

37. Klopper-Kes A, Meerdink N, Wilderom C. Effective cooperation influencing performance :a study in Dutch hospitals. Int J Qual Health Care. 2011;23:94-9.

38. Umar A, Boland C, JP T. Revised Bethesda guidelines for hereditary nonpolyposis colorectal cancer (lynch syndrome) and microsatellite instability. J Natl Cancer Inst. 2004;96(4):261-8.

39. Vasen $\mathrm{H}$, Watson P, Mecklin J, et al. New clinical criteria for hereditary nonpolyposis colorectal cancer (HNPCC, Lynch syndrome) proposed by the International Collaborative group on HNPCC. Gastroenterology. 1999;116: $1453-6$.

40. Cragun D, DeBate RD, Vadaparampil ST, Baldwin J, Hampel H, Pal T. Comparing universal lynch syndrome tumor-screening programs to evaluate associations between implementation strategies and patient follow-through. Genet Med. 2014;16(10):773-82.

41. Moore GF, Audrey S, Barker M, Bond L, Bonell C, Hardeman W, et al. Process evaluation of complex interventions: Medical Research Council guidance. BMJ. 2015;350:h1258.

\section{Ready to submit your research? Choose BMC and benefit from:}

- fast, convenient online submission

- thorough peer review by experienced researchers in your field

- rapid publication on acceptance

- support for research data, including large and complex data types

- gold Open Access which fosters wider collaboration and increased citations

- maximum visibility for your research: over $100 \mathrm{M}$ website views per year

At BMC, research is always in progress.

Learn more biomedcentral.com/submissions 